\title{
Benchmarking Hospital Performance Using Health Analytics
} Viju Raghupathi ${ }^{{ }^{*}}$ and Wullianallur Raghupathi ${ }^{2}$

${ }^{1}$ Brooklyn College, City University of New York, 2900 Bedford Avenue, Brooklyn, NY 11210, USA

${ }^{2}$ Graduate School of Business, Fordham University, New York, NY

\begin{abstract}
Background: The objective of this study is to investigate hospital performance using an emerging analytics approach. Given that hospital care accounts for a large segment of healthcare spending, it is essential that hospital performance be measured over time to determine whether and where there is room for improvement in some of its critical success factors, and if there are savings to be found.
\end{abstract}

Methods: Employing indicators such as hospital cost, in-hospital death rate, length of hospital stay, and the number of discharges from the hospital, we look at the trends for these indicators over a 10-year period. Data was extracted from the National Statistics Database of the Healthcare Cost and Utilization Project (HCUP.net), and Cognos and Tableau were used as visualization and analysis tools.

Results: Our central finding is that over the 10-year analysis period, U.S. hospitals improved in several areas, including reduction in length of stay in hospitals, reduction in number of in-hospital deaths, and increase in number of discharges from hospitals. Despite these improvements, however, the cost of healthcare rose significantly.

Conclusions: We show how healthcare administrators can learn from past performance in determining where to focus attention and improve outcomes. We also present a global perspective of healthcare and propose how critical it is for the U.S. to focus on major reduction in healthcare costs, beginning with hospital charges.

Keywords: Hospital performance; Healthcare; Analytics; In-hospital death; Length of stay; Discharge; Cost; Analytics; Cognos; Visualization

\section{Research Background}

Prior studies make it clear that analyzing hospital performance is critical to healthcare at national and global levels for lowering costs, improving patient outcomes, and improving overall quality of care. On a global level, the Organization for Economic and Cooperative Development (OECD) has determined that 20 to $40 \%$ of a country's total health expenditure should be on hospital care. On a national level, the general expectation is that efficiency of hospitals in terms of patient treatment and care improves over time [1]. Meanwhile, a study of healthcare across the U.S. shows a range of quality, inviting more analysis of internal performance factors to help professionals address these quality discrepancies [2].

Hospital care accounts for the largest share (32\%) of the U.S. healthcare expenditures, followed by physician/clinical services (21\%), prescription drugs (10\%), nursing home care $(6 \%)$, home and healthcare (2\%) [3]. Given that this is a large segment of healthcare spending, it is essential that hospital performance be measured over time to determine whether and where a) there is room for improvement in some of its critical success factors, and b) there are savings to be found.

Of industrialized nations worldwide, the U.S spends the most on healthcare and the most on healthcare per capita, even though the quality of healthcare by specific measurements remains relatively low. In 2010, the U.S. spent one and half times as much as any other country on healthcare and twice the average of the Organization for Economic and Cooperative Development [4]. Continuing this trend, in 2011, aggregate U.S. hospital spending was $\$ 387.3$ billion, a $63 \%$ increase from 1997; and the average cost of hospital stay per person was $\$ 10,000$, a 47\% increase from 1997 [5]. The overall healthcare spending was $\$ 2.8$ trillion, a $3.7 \%$ increase from the previous year and constituting $17.9 \%$ of the gross domestic product [6].

Over the past years, the U.S has seen an increase in life expectancy and a decrease in most types of mortality. Nevertheless, compared to other OECD high-income countries that have demonstrated a similar trend, U.S. has not moved up the rankings for critical health care indicators such as cost, death occurrence, length of stay, and total number of discharges.

A 2013 survey of 11 countries conducted by the Commonwealth Fund showed that, compared to other countries, adults in the U.S. were more likely to forego healthcare due to the high cost [7]. The United States Health Data for 2013 shows that the spending on health per capita for 2011 was $\$ 8508$, about two and a half times the OECD average of $\$ 3339$ and twice that of such wealthy European countries as France and Sweden. The healthcare cost for the U.S is more than that of Norway, the country in the OECD with the second highestincome. The total spending on healthcare in the U.S for the years 2000 to 2009 showed a yearly average increase of $4.4 \%$, while the growth rate declined by almost half to $2.1 \%$ [4]. Among OECD countries, the Commonwealth Fund ranked the U.S. lowest in terms of healthcare quality and at the top of the list in terms of cost [5].

In this research, we use an analytics framework to analyze changes in hospital performance over time in four key areas: cost of hospital stay, length of hospital stay, the number of hospital discharges, and the number of in-hospital deaths. All individuals are directly or indirectly impacted by health services, making the cost of healthcare a significant societal factor. We identified several key indicators for hospital performance, including reduction in hospital length of stays, reduction

*Corresponding author: Viju Raghupathi, Brooklyn College, City University of New York, 2900 Bedford Avenue, Brooklyn, NY 11210, USA, Tel: 732-485-7952; E-mail:VRaghupathi@brooklyn.cuny.edu

Received March 18, 2015; Accepted April 22, 2015; Published April 27, 2015

Citation: Raghupathi V, Raghupathi W (2015) Benchmarking Hospital Performance Using Health Analytics. J Health Med Informat 6: 188. doi:10.4172/2157-7420.1000188

Copyright: ( 2015 Raghupathi V. This is an open-access article distributed under the terms of the Creative Commons Attribution License, which permits unrestricted use, distribution, and reproduction in any medium, provided the original author and source are credited. 
in in-hospital deaths, reduction in or prevention of an increase in the cost of healthcare, and optimization of the rates of admittance in emergency departments/other hospitals/long term care. For each of these key performance indicators, benchmarks were developed for the sake of comparison. The length of stays and in-hospital deaths are compared for conditions or procedures that require similar stay or have similar deaths rates. The cost of healthcare is compared across various conditions or procedures. The growth trend in cost is rationalized and compared to the overall growth in cost and change in macroeconomic conditions. Admittance rates for various conditions and/or procedures are compared, and optimization rates established. We looked for combinations of indicators that generate meaningful results and offer insight on hospital performance. The expectation is that hospitals will become more efficient, providing appropriate patient services without a dramatic increase in costs over time.

In the domain of healthcare, analytics is an excellent decision support technology. It enables physicians, nurses, health officials, health policy makers, and other healthcare entities to make better and faster health decisions [8]. We show in a trend analysis how the indicators of hospital performance function. The data are extensively analyzed using the business intelligence and visualization tools of Tableau and Cognos Insight. Relationships between indicators are established using the advanced statistical modeling technique of linear regression. Through our analysis, we offer empirical and conceptual insights to hospitals in maximizing their operational efficiency.

\section{Hospital performance}

According to the national study on in-patient hospital stays by the Agency for Healthcare Research and Quality, there were 38.6 million hospital stays in 2011, an $11 \%$ increase from 1997. During this time frame, total hospital costs rose to $\$ 387.3$ billion, a $63 \%$ increase. The mean charges per stay - the amount a patient pays to the hospital for all charges relating to the stay, including room, nursing and tests - was $\$ 35,400$ in 2011, more than twice the amount in 1997. Meanwhile, the number of discharges against medical advice increased $41 \%$ over the years from 1997 to 2011 [5].

Since the passage of the Patient Protection and Affordable Care Act in 2010, more attention has been given to efficient delivery of healthcare by healthcare administrators, continuous improvement in quality of care and patient safety, promotion of health information technology (electronic medical records), and reduction of per capita spending on healthcare. A report by Health Grades Inc. on hospital performance in over 4500 U.S. hospitals (relating to 31 of the most common inpatient procedures and conditions during the years 2010 through 2012) shows that there are quality disparities within hospitals among different procedures/conditions, as well as between hospitals within local services [9]. The report also suggests the impact that patient mortality (in-hospital deaths) and patient complications have on healthcare cost, and it advances the theory that the root causes of cost in terms of mortality and complications can be reduced through the use of minimally invasive surgical techniques [9].

At a global level, healthcare expenditures show considerable variation across countries in terms of per capital spending and other trends. (Note that except for Mexico and the U.S., all OECD countries have universal or quasi-universal health coverage [4]. Between 2009 and 2011, many countries reduced spending in an effort to cut the budget deficit or government debt. Canada and the U.S., however, increased healthcare spending during this period. That said, the overall health of a population is influenced by many factors, but the most important of these is the performance of its healthcare system, not the costs associated with it.

\section{Methods}

Our research involves the use of analytics in the healthcare domain and adopts a framework of health analytics that is based on the general framework of business intelligence and data warehousing [10]. The framework is generic enough to be applied to any healthcare context in which analytics is deployed. It includes the components of data collection, data transformation, analytics platform and tool selection, and analytics applications. Figure 1 depicts our analytics framework.

Typically, healthcare data is aggregated from several sources, such as hospitals, clinical laboratories, radiology centers, insurance companies, and public health systems (e.g. CDC, HHS, WHO). Due to the disparate nature of the sources, the data may lack uniformity in representation and coding. The raw data, therefore, needs to be reconciled in terms of structure and format, to be readied for analysis. The process of ETL (extraction-transformation-loading) readies the data for analytics. Once the data are prepared, they are loaded into a data warehouse managed by one or more warehouse servers, known as relational database management systems (RDBMS). Using RDBMS, sophisticated queries that use query structures, optimizations, and query processing techniques are performed on the data in the data warehouse. Large data warehouses sometimes have multiple RDBMSs that run in parallel, performing multidimensional querying and analyses at high speeds, a process referred to as online analytical processing (OLAP). Some analytics operations in OLAP include filtering, aggregation, drilling down and pivoting. In addition to querying, reporting servers facilitate definition, execution and the generation of accurate reports used for decision-making. Supplementing the reporting and querying servers are the data mining engines that further enable multi-dimensional OLAP (MOLAP), allowing users to define and publish cubes (of data) for high-speed and sophisticated processing.

\section{Data collection}

For our study, hospital performance data was downloaded from the National Statistics Data of the Healthcare Cost and Utilization Project website HCUP.net. The HCUP encompasses the largest collection of longitudinal hospital care data in the U.S. (https://www.hcup-us. ahrq.gov/). As shown in Table 1, the hospital performance indicators included in our analysis were in-hospital deaths, hospital cost, lengths of stay in hospital, and patient discharges - all crucial in determining the performance of hospitals in the overall healthcare system. The unit of data collection for the indicators shown in the table was their use per 100,000 . The principal CCS principal diagnosis category, CCS principal diagnosis category name, and year were used as filters.

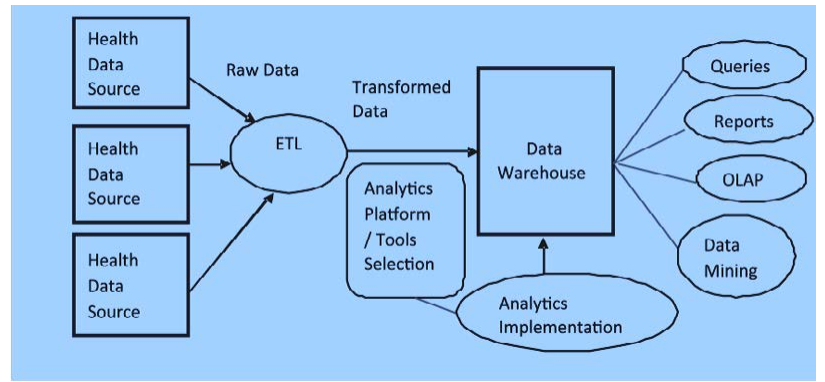

Source: Raghupathi and Raghupathi, 2013a

Figure 1: Analytics framework. 


\begin{tabular}{|c|c|}
\hline Indicators & Definition \\
\hline CCS principal diagnosis category & Clinical Classifications Software principal diagnosis category \\
\hline CCS principal diagnosis name & Clinical Classifications Software principal diagnosis name \\
\hline Year & Year the data relates to \\
\hline Total number of discharges & Number of patients leaving the hospital after receiving care \\
\hline Rate of discharges per 100,000 persons & Number of patients leaving the hospital after receiving care per 100,000 persons \\
\hline LOS (length of stay) & $\begin{array}{c}\text { Number of nights the patient remained in the hospital for his or her stay. A patient admitted and discharged } \\
\text { on the same day has a length of stay equal to } 0 .\end{array}$ \\
\hline Charges, \$ (mean) & $\begin{array}{c}\text { Amount of hospital billing for the entire hospital stay (not including physician fees). We use the terms costs } \\
\text { and hospital charges interchangeably. }\end{array}$ \\
\hline Aggregate charges, $\$$ (the "national bill") & Sum of all costs for all hospital stays. \\
\hline Admitted from emergency department Number, Rate & Number and rate of patients admitted from the emergency department \\
\hline Admitted from other hospital Number, Rate & Number and rate of patients admitted from other hospitals \\
\hline Admitted from long term care number, Rate & Number and rate of patients admitted from long-term care \\
\hline In-hospital deaths Number/Rate & Number and rate of patient deaths during hospital stay \\
\hline Routine discharge Number/Rate & Number and rate of patients routinely discharged \\
\hline Discharge to another short-term hospital & Number of Patients discharged to another short-term hospital \\
\hline Discharge to another institution & Number of Patients discharged to another healthcare institution \\
\hline Discharge to home health care & Number of Patients discharged to home health care \\
\hline Against medical advice (AMA) number & Number of patients who leave the hospital against the advice of their doctor. \\
\hline
\end{tabular}

Table 1: Hospital performance indicators.

Using analytics, we identified trends in the significant indicators of hospital performance over the time period 1997 to 2006. Among other questions, we asked:

- Have hospital costs changed over the 10-year time period from 1997 to 2006 ?

- Has there been a reduction in hospital deaths over the 10year time period 1997 to 2006 ?

- Has there been a reduction in the length of stay in the hospital over the 10-year time period 1997 to 2006 ?

- Has there been a reduction in the total number of discharges over the 10-year time period 1997 to 2006 ?

\section{Data transformation}

In order to analyze raw data extracted from the Agency for Healthcare Research and Quality it must be reconciled in terms of structure and format. Quality issues were corrected by integrating, cleansing, and standardizing the data through the steps of extract, transform, and load [11].

\section{Analytics platform and tool selection}

Once the data are transformed, a suite of tools is utilized to perform different types of analytics. It is typical to have a combination of business intelligence tools for analytics. We selected Cognos Studio and Tableau as the business intelligence tools. The Cognos Studio platform is very effective for time series analysis of data. Tableau, especially practical for its trend line function, was used for data visualization. Analysis consisted of manipulating different indicators to find significant trends and patterns in the data. Specifically, we deployed linear regression for the Tableau trend line application.

\section{Analytics applications}

Using the selected tools, different types of analytics was performed in the context of queries, reports, online analytical processing and data mining. The data that are cleansed and readied are then loaded into Cognos and Tableau for analysis. We utilized Cognos Studio tools for querying, reporting. We utilized the data mining techniques of ranking, association and visualization. We also used the online analytical processing functions of filtering, aggregation, drilling down, and pivoting of data. For display, we used the dual display feature of chart and table. We also relied heavily on Tableau's visualization using scatter plots, highlight tables, and trend line features. The results of our analysis offer insight into the trends in hospital performance and help us better assess the state of healthcare performance at a national level.

\section{Results and Discussion}

Various analytical techniques were applied to reveal associations between indicators and to uncover patterns that offer insights into our propositions. Data was explored and analyzed in several ways, and we generated a total of 13 charts and tables. What follows is a discussion of our results for the different analyses.

\section{Healthcare charges and cost}

The trends in the mean healthcare costs for the U.S. displayed in Figure 2 show that healthcare costs, on average, have doubled in the years between 1997 and 2006, from $\$ 413,482$ to $\$ 908,172$. There is a general increase in cost across all diseases, but the largest increase appears to be for respiratory distress syndrome, followed by spinal cord injury $(\$ 790,573)$ and low birth weight and fetal growth retardation $(\$ 726,836)$. The diseases with the least cost are cancers of gastro intestinal organs and peritoneum.

To optimize performance and minimize cost given the wide range 
Citation: Raghupathi V, Raghupathi W (2015) Benchmarking Hospital Performance Using Health Analytics. J Health Med Informat 6: 188. doi:10.4172/21577420.1000188

mentioned above, hospitals would do well to monitor the utilization of their resources in terms of the cost for the various diseases. If the portfolio of every hospital is developed accurately, it may reveal opportunities within the healthcare system to offer specializations. From a hospital's perspective, a focus on one or more specialized areas provides an opportunity to increase prices for those specialized services and see decreasing costs associated with error.

\section{Healthcare charges and number of discharges}

An interesting finding is that the total healthcare cost in dollars is increasing at a faster rate than the number of discharges (Figure 3).

Since 2004, while the total number of discharges remained relatively stable, total charges have increased by $21 \%$, as shown in Figure 3. In fact, from 1997 to 2006, the charges have doubled. This finding indicates that hospitals are becoming more expensive without offering any incremental discharge benefit to patients.

\section{Hospital charges and in-hospital death rates}

During the analysis time frame of 1997 to 2006, in-hospital death rates decreased by $1 \%$, while the hospital charges doubled (increase of 101\%), illustrated in Figure 4.

Meanwhile, as Figure 4 also shows, in-hospital death rate remained at $8 \%$ through 2003 and decreased to $7 \%$ from 2004 to 2006. Again, since 1997, death rates have decreased and overall costs have increased. This trend indicates that hospitals have had fewer deaths meanwhile raising patient costs. The high charges may indicate that hospitals are either incurring higher costs or increasing their profit margin per patient (or both).

\section{Hospital charges and against medical advice}

Against medical advice (sometimes known as discharge against medical advice) is a healthcare term that refers to a patient leaving the hospital against the advice of his or her doctor. Even though leaving a hospital prematurely may be counter-productive to the patient's wellbeing, a patient (or their authorized representative) has the right to decline recommended treatment and to leave. Healthcare data suggests that patients discharged against medical advice have a four times higher rate of readmission within 30 days than other patients [12].

We found a statistically significant correlation between aggregate charges and against medical advice number for congestive heart failure. Figure 5 shows that the number of discharges against medical advice for congestive heart failure almost doubled from 6710 to 11,433 between the years 1997 to 2006 . The aggregate charges also more than doubled between these years, from $\$ 11,819,073,303$ to $\$ 32,762,953,824$. The positive correlation between the two indicators suggests that if hospitals minimize the increase in charges, the rate of discharges may also decrease. In the case of congestive heart failure, hospitals should try and lower the charges so that more patients can avail themselves of treatment recommended by their doctors. It is no great cause and effect leap of understanding from the fact of increased cost of a treatment

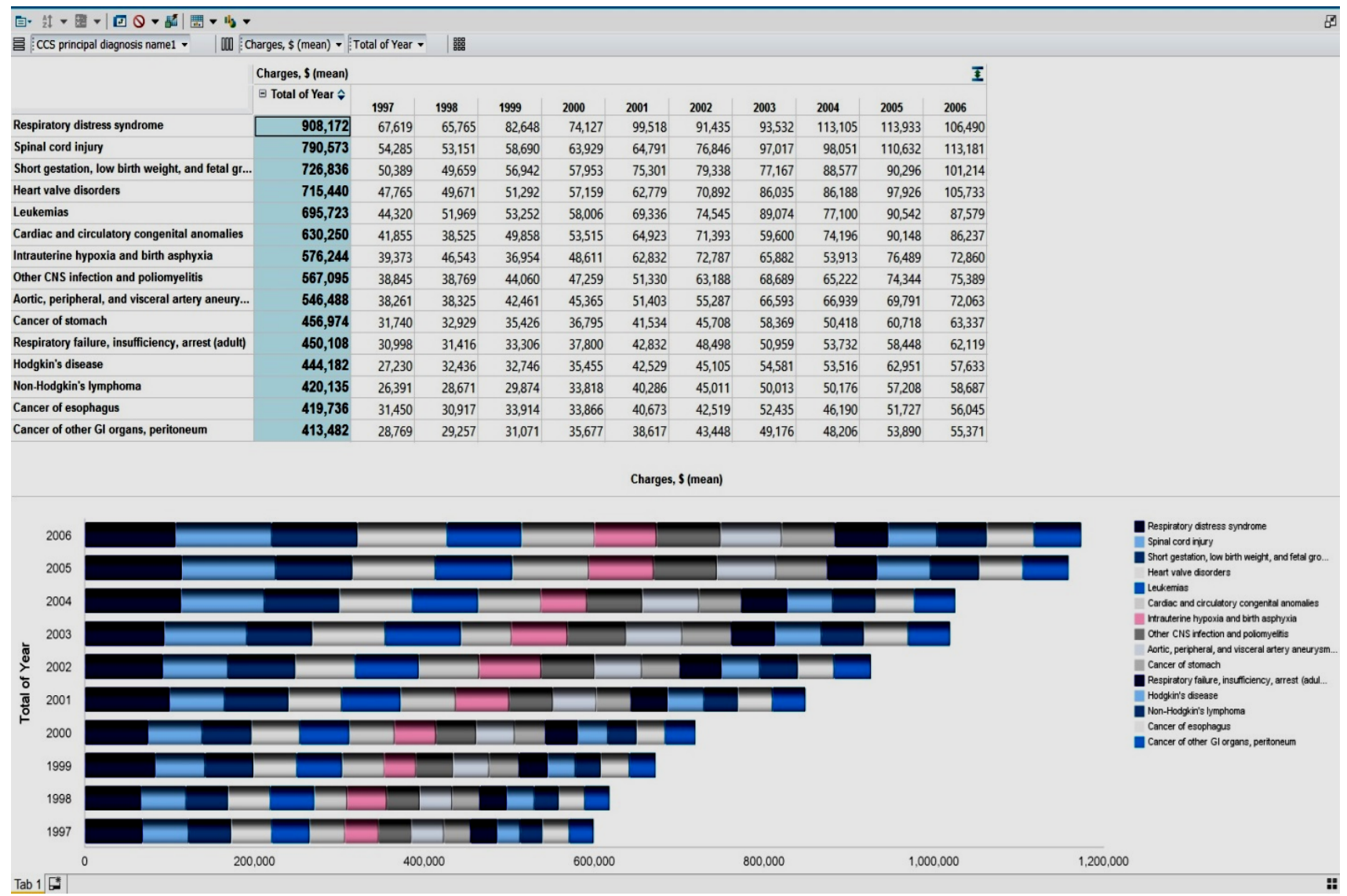

Figure 2: Trends in healthcare costs. 
Citation: Raghupathi V, Raghupathi W (2015) Benchmarking Hospital Performance Using Health Analytics. J Health Med Informat 6: 188. doi:10.4172/21577420.1000188

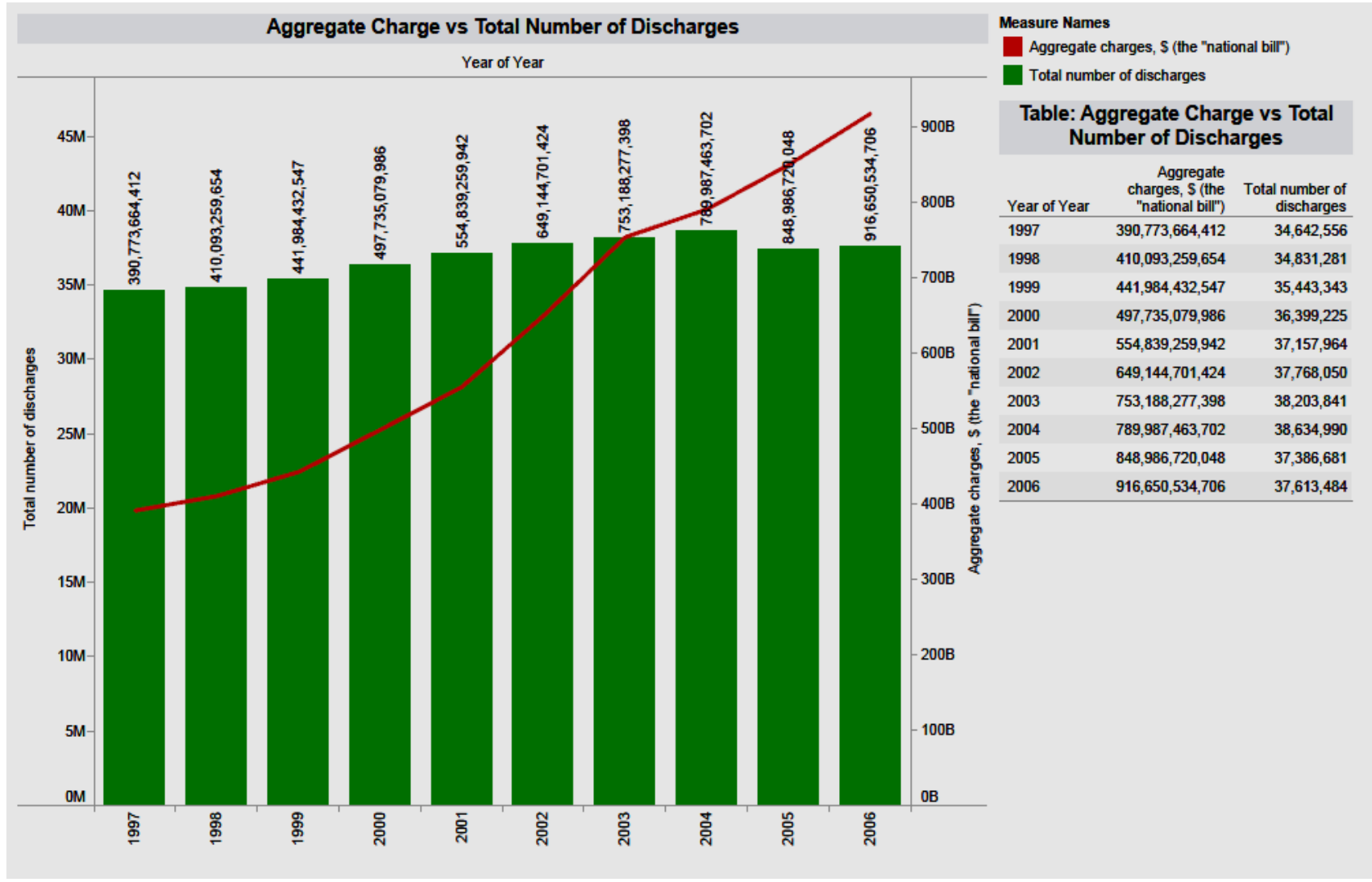

Figure 3: Aggregate charges vs. number of discharges.

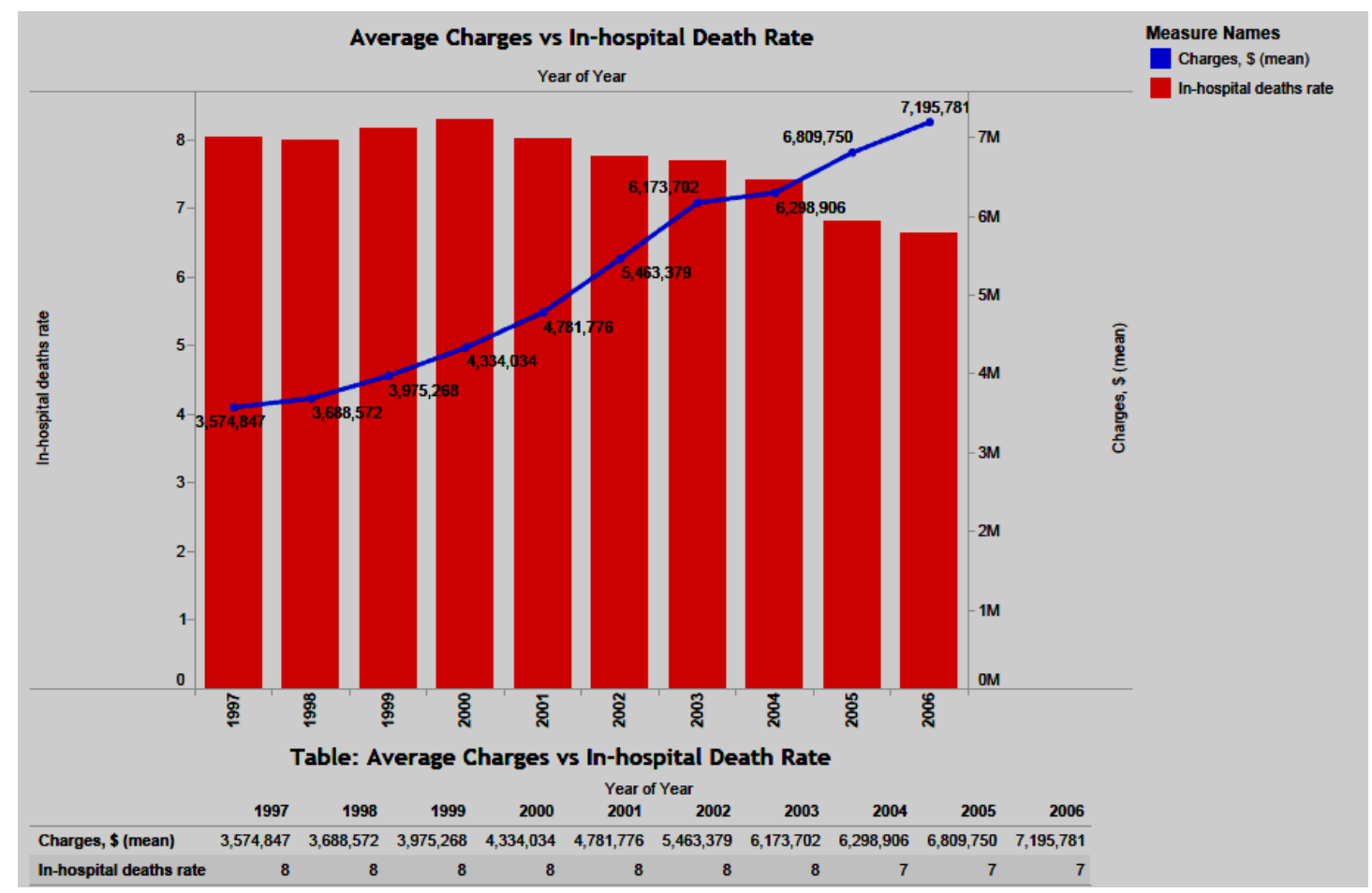

Figure 4: Average charges vs. in-hospital death rates. 


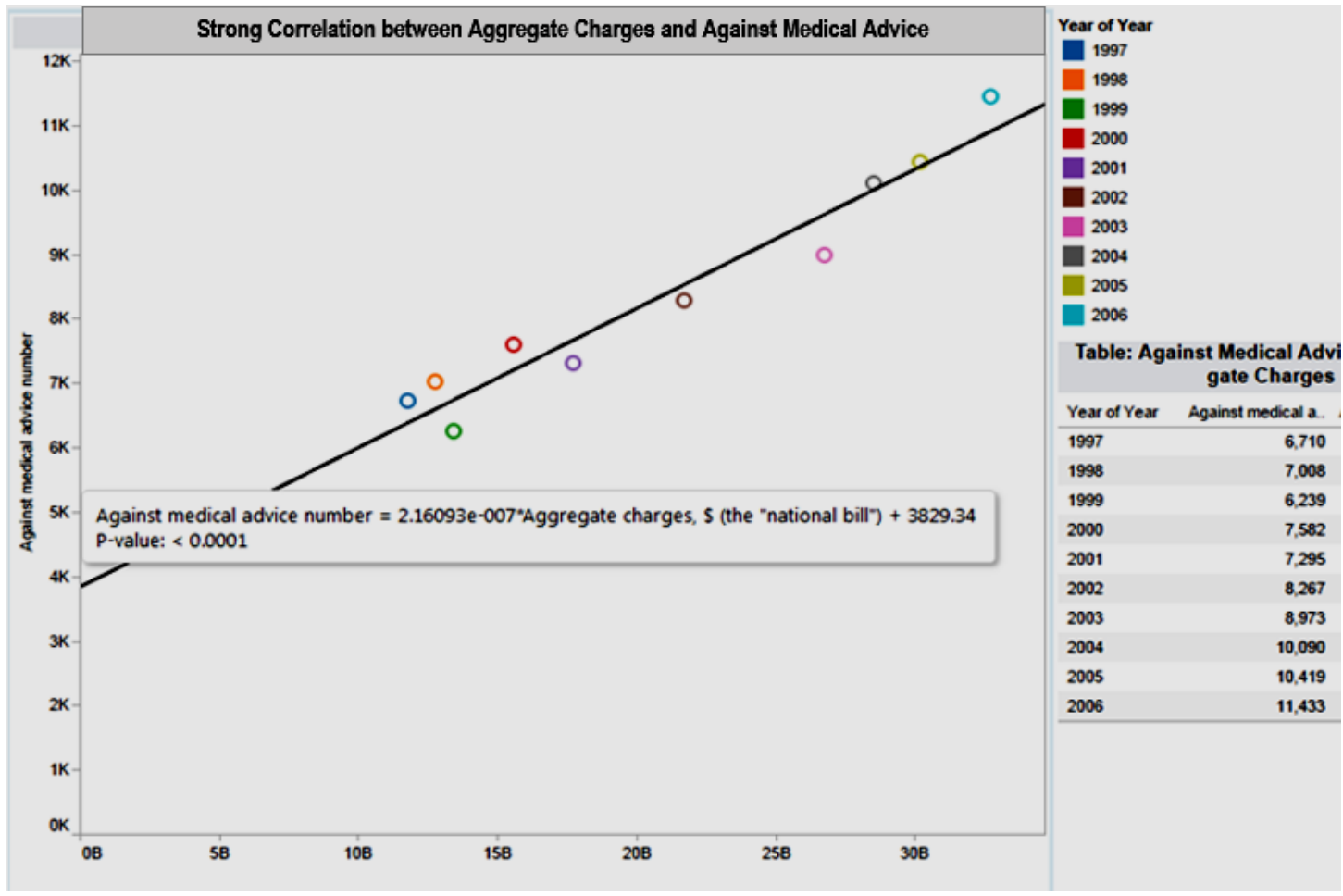

Figure 5: Average charges vs. against medical advice.

to the implication that patients may refuse treatment (and leave the hospital) against doctor's advice due to inability to meet those high charges.

\section{In-hospital death rate and length of stay}

Figure 6 shows the analysis for in-hospital death rate and the length of stay in the hospital.

We found that there is a statistically significant positive correlation between the length of stay and in-hospital death rate for liver cancer: the longer the stay, the higher the death rate. From 1997 to 2006, the death rate for liver cancer decreased by $15 \%$ from 0.178 to 0.15 . However, during this time frame, the length of stay also decreased by $7 \%$ from 7.379 to 6.851 . Thus, even though the death rate decreased over these years, it's important to recognize that this decrease can be attributed partly to the shortening in the length of stay at the hospital, which naturally lowers the chances for in-hospital deaths. As far as mortality goes, hospitals should aim to reduce the in-hospital death rate by improving the quality of service for diseases with a history of high mortality. From our analysis, because liver cancer has a high inhospital death rate, a better strategy for hospitals would be to focus on improving the quality of treatment for cancer patients and lower the in-hospital death rate. Obviously, cancer carries with it an inherent risk of in-hospital mortality. Hospitals should periodically evaluate patient portfolios and, when appropriate, transfer patients to other hospices or maintenance facilities for continued care.

\section{Hospital charges across diseases}

As shown in Figure 7, hospital charges vary across diseases. The mean charges are about $\$ 150,000$ while the range is from almost $\$ 0$ to $\$ 900,000$. Many factors may cause price disparities across diseases, or even across regions. These include hospital location, patient's health, disease stage, and severity of illness during admission. Transparency in hospital pricing is an alternative to keeping prices in check.

\section{Death rate and diseases}

As shown in Figure 8, there does not appear to be a correlation between death rates and the number of diseases.

For instance, the three most expensive diseases do not show the highest death rates. Pneumonia and acute cerebrovascular, two expensive diseases, have low death rates. Cardiac arrest, the least expensive disease, has one of the highest death rates.

\section{Rate of discharge and cost}

Figure 9 shows the rate of discharge for various diseases.

Live births have the highest rate of discharges of all, at about 1,416 per 100,000, and the rate increased 4\% from 1997 to 2006 . If this rate continues, live births will have an impact on the overall discharge rate for all diseases (and reasons for hospital stays). Coronary atherosclerosis has the second largest number of discharges at 448 per 100,000. Fluid and electrolyte has the lowest rate of discharges at about 187 per 100,000 . Controlling the discharge rate is important to addressing healthcare expenses. Premature discharges may trigger readmissions, adding to cost. Hospitals should monitor closely the discharge rate in an effort to control long-term costs and improve the quality of service.

\section{In-hospital death number and diseases}

Figure 10 shows the distribution of in-hospital death numbers for various diseases.

As shown in Figure 10, septicemia and pneumonia are conditions that see a high number of deaths or a high risk for death while in the 


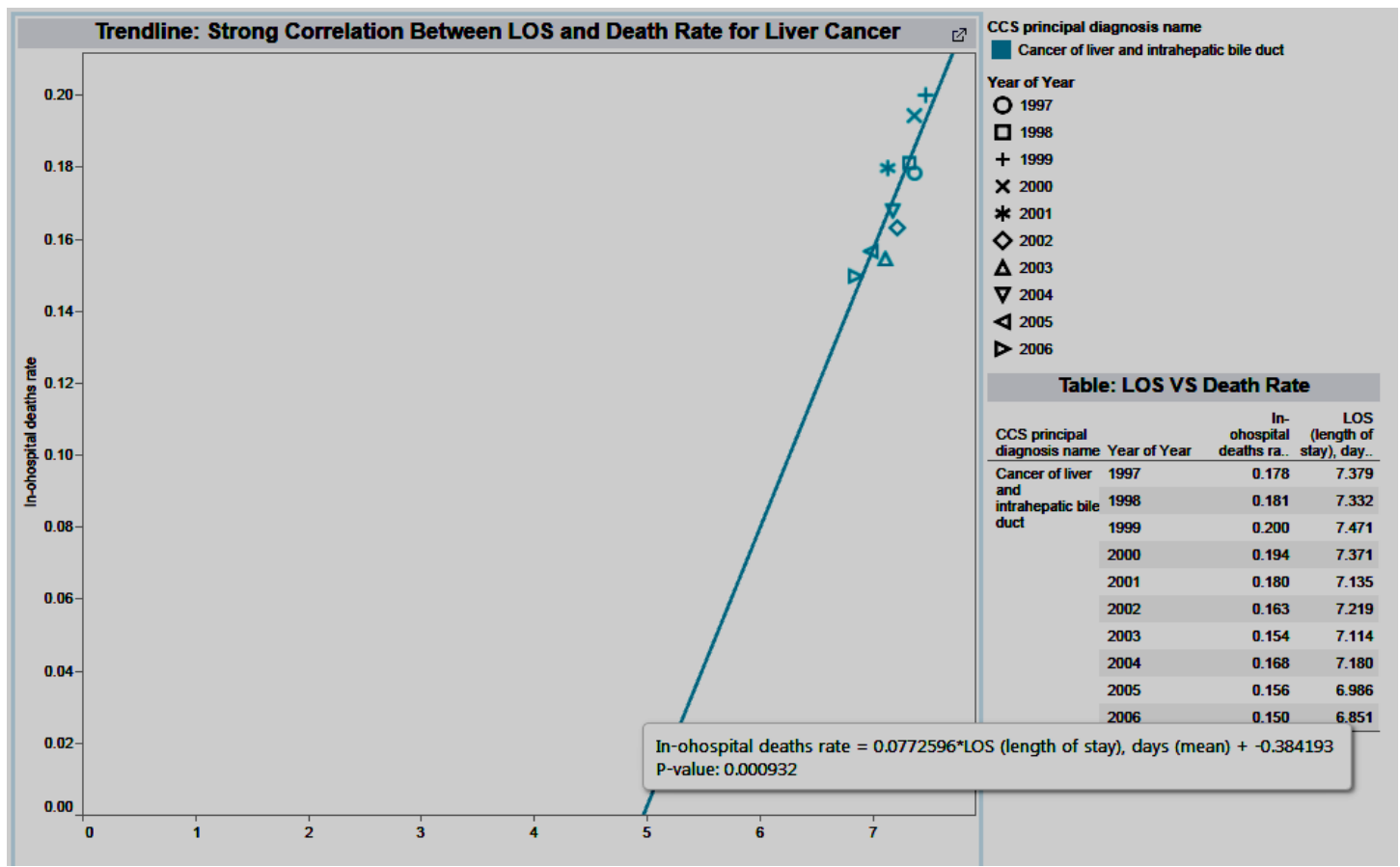

Figure 6: In-hospital death rate and length of stay (LOS).

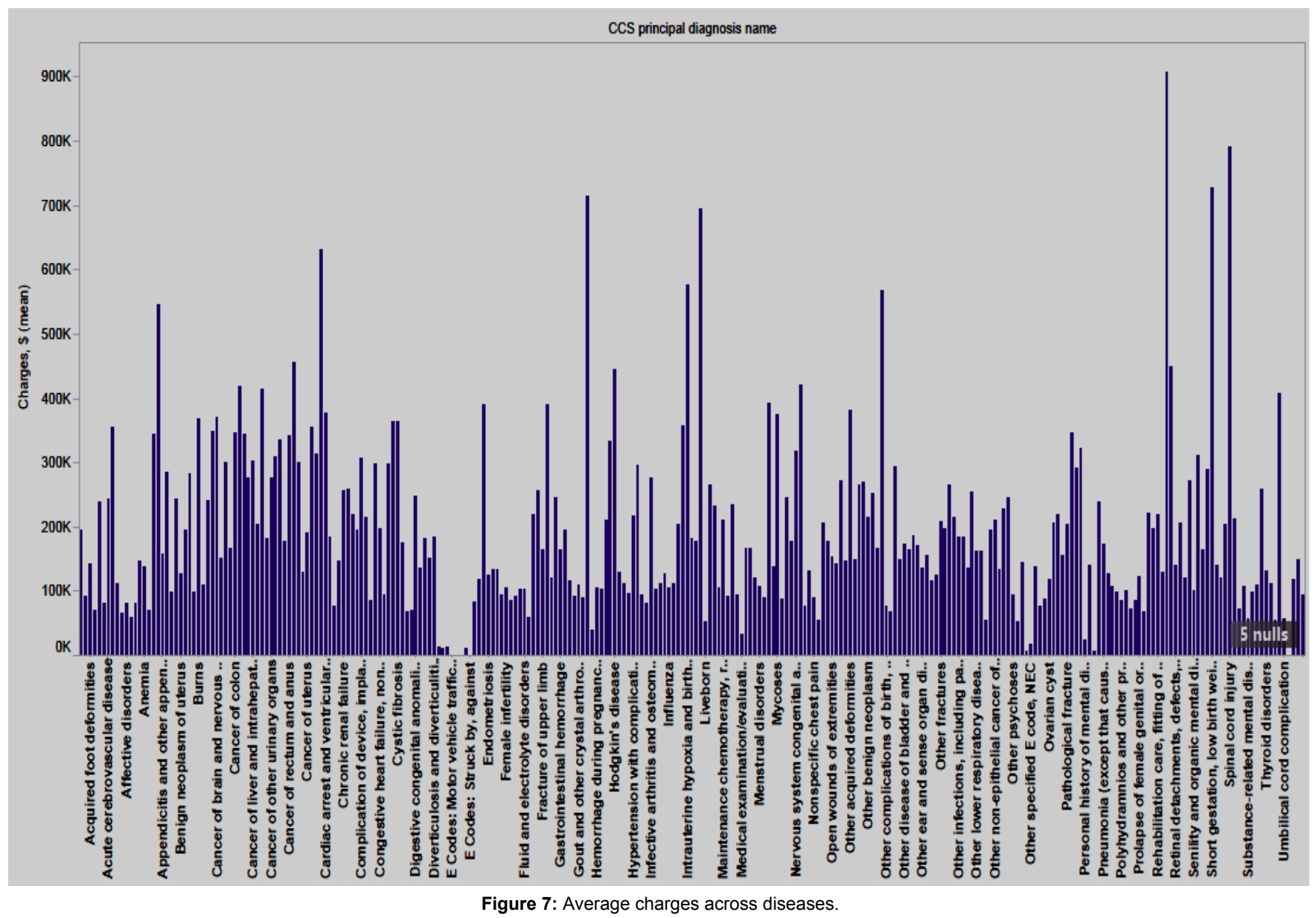


Citation: Raghupathi V, Raghupathi W (2015) Benchmarking Hospital Performance Using Health Analytics. J Health Med Informat 6: 188. doi:10.4172/2157-

Death Rate and Number of All Diseases

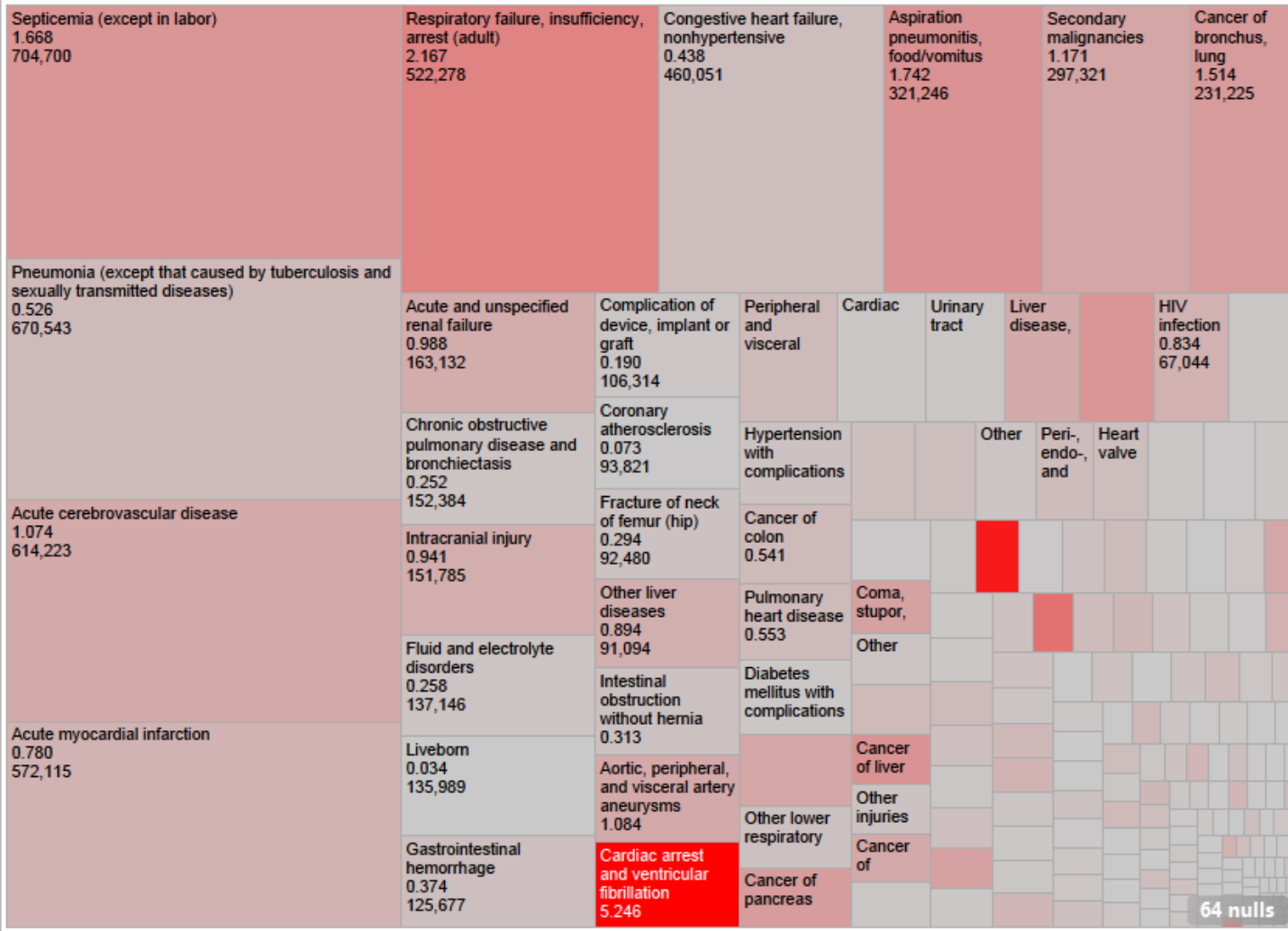

In-ohospital deaths rate

0.001

Table: Death

Rate/\# vs All Diseases

CCS principal .. In-hospi

Abdominal her.. Abdominal pain

Acquired foot .

Acute and chr.

Acute and uns.

Acute bronchit.

Acute cerebro.

Acute myocar.

Acute posthe..

Administrative.

Affective disor.

Alcohol-relate.

Allergic reacti..

Anal and recta.

Anemia

Anxiety, soma.

Aortic and peri.

Aortic, periphe

Appendicitis a.

Aspiration pne.

Asthma

Bacterial infec.

Benign neopla.

Biliary tract di.

Birth trauma

Figure 8: Death rate and number of diseases.

\begin{tabular}{|c|c|c|c|c|c|c|c|c|c|c|c|}
\hline \multirow[t]{3}{*}{ G CCS principal diagnosis name1. } & te of discharges per 1 & .000 persons & Total o & ear. & 烈 & & & & & & \\
\hline & \multicolumn{11}{|c|}{ Rate of discharges per 100,000 persons } \\
\hline & $\exists$ Total of Year $\hat{\nabla}$ & 1997 & 1998 & 1999 & 2000 & 2001 & 2002 & 2003 & 2004 & 2005 & 2006 \\
\hline Liveborn & $1,415.58$ & $1,385.3$ & $1,361.6$ & $1,377.2$ & 1.454 .4 & $1,403.7$ & $1,444.5$ & $1,409.6$ & $1,451.3$ & $1,430.8$ & $1,437.4$ \\
\hline Coronary atherosclerosis & 448 & 516.1 & 476.3 & 447.3 & 482.2 & 491.3 & 449.4 & 433.1 & 407.2 & 375.5 & 401.6 \\
\hline Pneumonia (except that caused by tuberculo... & 446.37 & 451.7 & 470.7 & 491.6 & 443.1 & 428.8 & 443.3 & 453.1 & 414.4 & 458.6 & 408.4 \\
\hline Congestive heart failure, nonhypertensive & 368.4 & 363.6 & 365.6 & 355 & 363.4 & 368.4 & 367.7 & 386 & 377.2 & 368.9 & 368.2 \\
\hline Nonspecific chest pain & 271.41 & 197.2 & 226.6 & 241.9 & 281.3 & 307.1 & 307.7 & 297.2 & 288.8 & 279.1 & 287.2 \\
\hline Trauma to perineum and vulva & 268.75 & 261.5 & 261.8 & 260.3 & 290.8 & 267.9 & 279.6 & 257.9 & 268.1 & 265.5 & 274.1 \\
\hline Acute myocardial infarction & 255.95 & 268.6 & 272.9 & 261.7 & 272.4 & 271.6 & 265.7 & 258.8 & 237.4 & 224.1 & 226.3 \\
\hline Cardiac dysthythmias & 233.29 & 209.9 & 213.3 & 215.8 & 231.1 & 247.2 & 247.8 & 244.1 & 236.9 & 235.7 & 251.1 \\
\hline Other complications of birth, puerperium affe... & 224.8 & 145.3 & 154.8 & 220.5 & 241.5 & 225.2 & 241.2 & 245.5 & 259 & 257.8 & 257.2 \\
\hline Chronic obstructive pulmonary disease and $\mathrm{b} . .$. & 211.58 & 202.2 & 219.3 & 230.6 & 219.4 & 211.7 & 215.3 & 214.1 & 189.7 & 213.2 & 200.3 \\
\hline Spondylosis, intervertebral disc disorders, ot... & 211.17 & 196.7 & 198.8 & 194.1 & 208.3 & 224.3 & 220.3 & 226.9 & 210.3 & 218.9 & 213.1 \\
\hline Acute cerebrovascular disease & 200.24 & 225.9 & 224.4 & 210.8 & 205.6 & 202.3 & 196.1 & 192.9 & 186.5 & 178 & 179.9 \\
\hline Complication of device, implant or graft & 195.76 & 180.3 & 171.8 & 179 & 186.9 & 202.8 & 204.8 & 205.8 & 205.3 & 208.4 & 212.5 \\
\hline Osteoarthritis & 189.94 & 153.2 & 148.6 & 149.2 & 157 & 176 & 192.3 & 201.6 & 225.2 & 249.9 & 246.4 \\
\hline luid and electrolyte disorders & 186.92 & 1717 & 1697 & 1821 & 1816 & 1997 & 3 & 200.2 & 4 & 1942 & \\
\hline
\end{tabular}

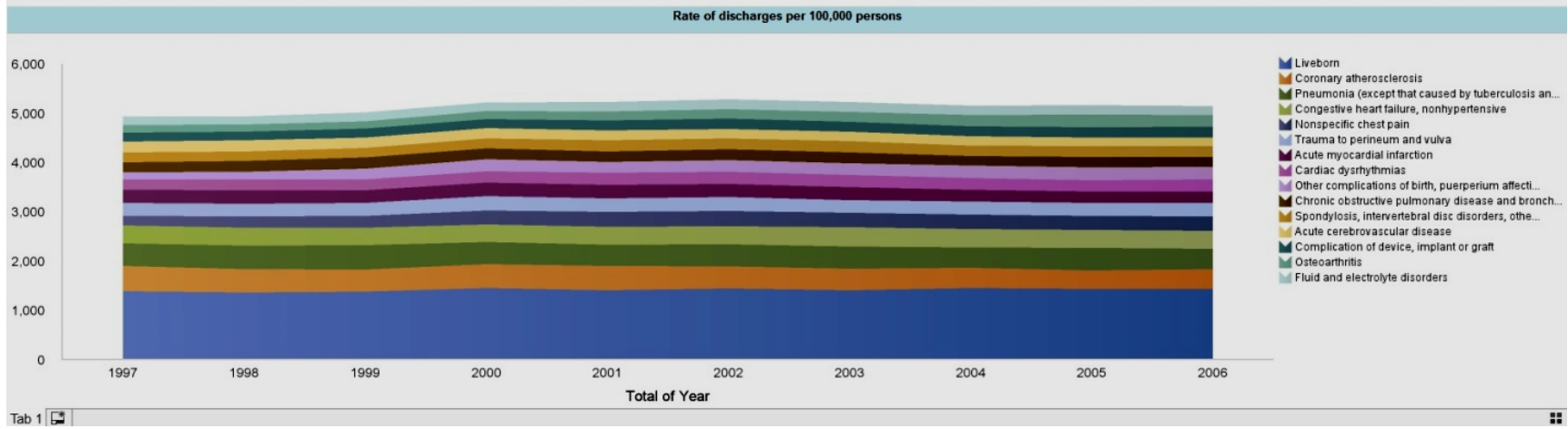

Figure 9: Rate of discharge. 


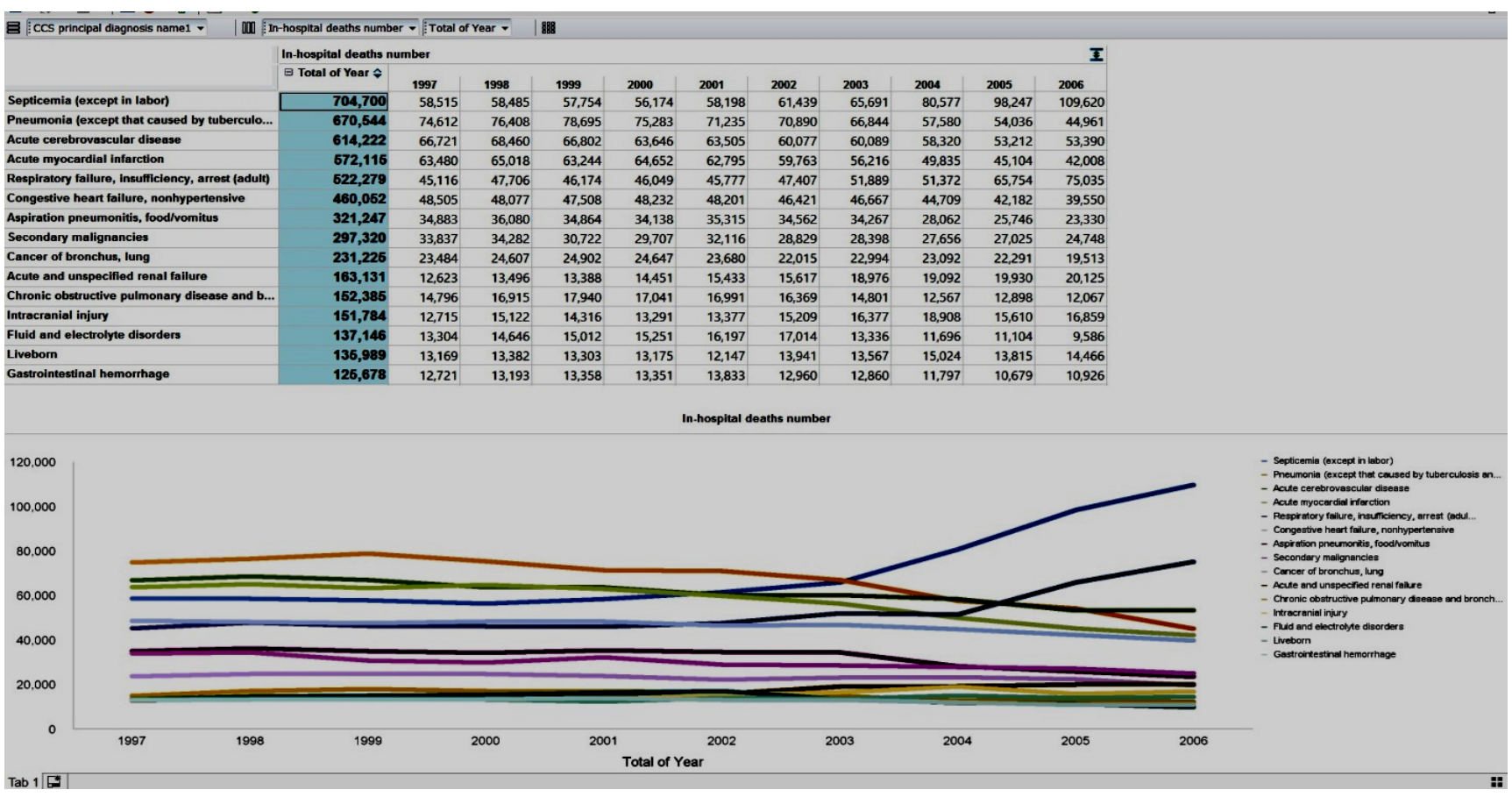

Figure 10: In-hospital death number and diseases.

hospital. The chart indicates that septicemia increased dramatically from about 66,000 in 2003 to about 110,000 in 2006. Gastrointestinal hemorrhage has the lowest in-hospital death number, about 126,000 , and also shows a decreasing trend from 1997 to 2006. Fluid and electrolyte disorder is another condition that shows a decreasing trend during this timeframe. To reduce in-hospital death rates and develop solutions for improving the quality of patient care during stays, hospitals need to consider the variation in these death number trends and determine which diseases to focus on.

\section{Length of Stay, admitted from long-term and admitted from emergency}

Figure 11 shows the trend for Length of Stay, the number admitted from long-term care and the number admitted from emergency care.

The analysis of the model for Length of Stay and the number from the two modes of admission - long-term care and emergency care - was significant $\left(\mathrm{R}^{2}\right.$ is close to $1 ; \mathrm{p}$-value $\left.<0.0001\right)$ (Figure 11). In Figure 11, the numbers admitted from long-term care are in columns, and the numbers admitted from emergency care are in rows. CCS principal diagnosis is the filter. For acute cerebro-vascular condition, the number admitted from long-term care and from emergency care showed a significant relationship. For others, such as abdominal hernia, abdominal pain, acute and unspecified renal failure, acute bronchitis, acute myocardial infraction, and affective disorders, the length of stay and the number admitted from long-term care and emergency care show a significant relationship. In general, the number admitted from long term care and emergency care decreased considerably with the same length of stay for these diseases. This can be attributed to the fact that hospitals have been able to efficiently control and/or treat these particular diseases.

\section{Discharge of patients to different healthcare providers}

Figure 12 shows our analysis of the distribution of patient discharges to short-term hospitals, rehabilitation centers and nursing homes (and other institutions), and home health care in the year 2006.

That year, osteoarthritis had the highest number of patients discharged to home care and to rehabilitation/nursing homes. Where short-term hospitals are concerned, coronary atherosclerosis had the highest number, and gastrointestinal hemorrhage had the lowest; for home care, osteoarthritis had the largest number of discharges, and fluid and electrolyte disorder had the lowest; and for discharge to nursing home or rehabilitation centers, osteoarthritis had the largest number while diabetes mellitus with complications had the lowest. This information is useful in discharge planning evaluation, which determines a patient's care needs after leaving the hospital setting. Hospitals should be prepared to transfer medical records with ease to other institutions, as well as perform appropriate needs assessments, depending on where the patient is being transferred.

\section{Length of stay and against medical advice}

Figure 13 shows the distribution of the length of stay and against medical advice.

The model for length of stay and the number discharged against medical advice has been significant for the years 1997 to 2006 (R2=0.6; $\mathrm{p}<0.05$ ). As shown in Figure 13, the total numbers for Length of Stay and those leaving Against Medical Advice have decreased over this 10year period, demonstrating considerable improvement in quality of hospital service.

\section{Total number of discharges and in-hospital deaths for each disease}

Figure 14 shows the total number of discharges and the number of in-hospital deaths.

The model for total number of discharges and in-hospital deaths is significant for the 10 -year time period $(\mathrm{R} 2=0.997$, $\mathrm{p}$-value $<0.0001)$, 
Citation: Raghupathi V, Raghupathi W (2015) Benchmarking Hospital Performance Using Health Analytics. J Health Med Informat 6: 188. doi:10.4172/21577420.1000188

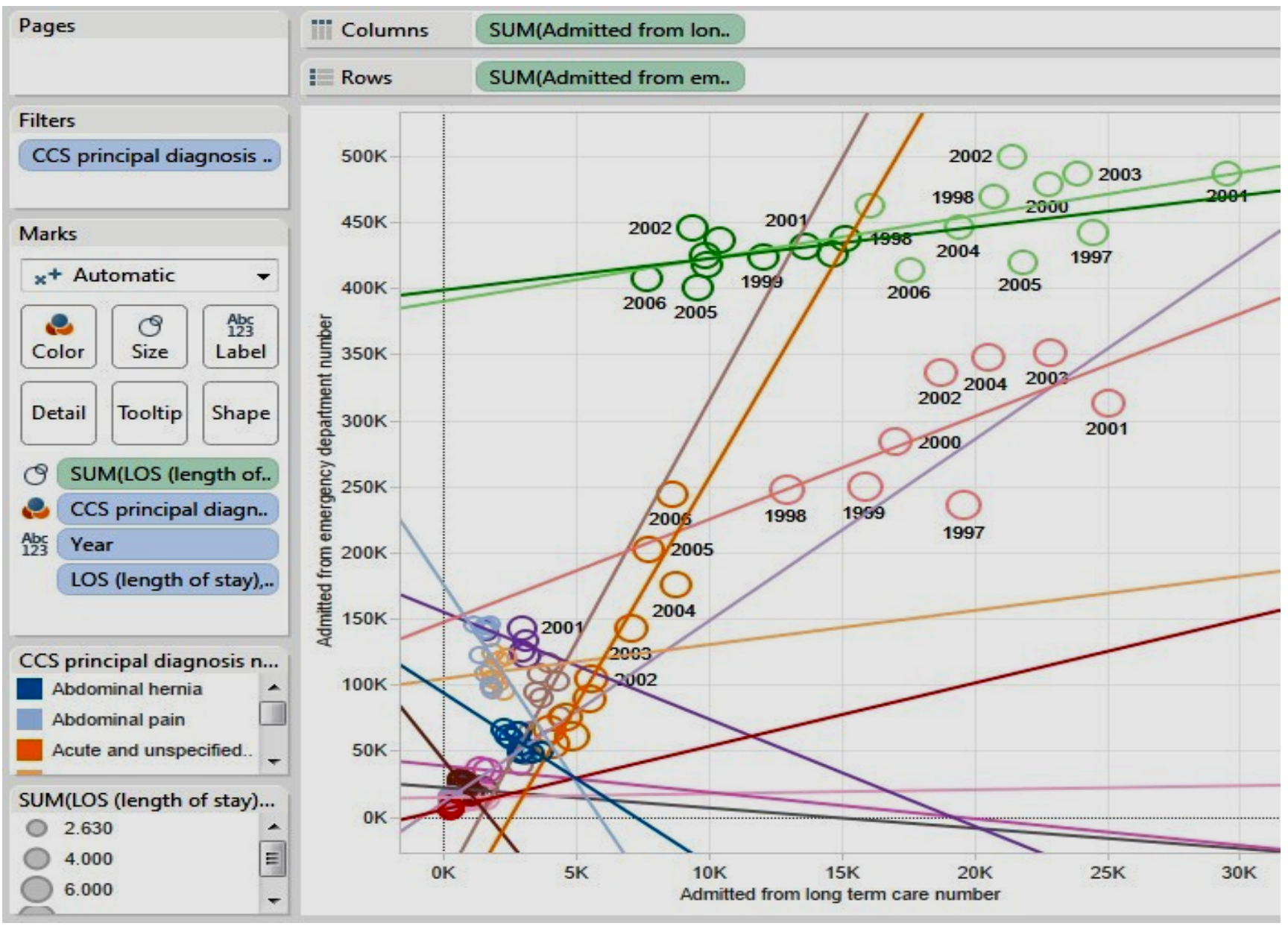

Figure 11: Trend line for length of stay, admitted from long-term care and admitted from emergency.

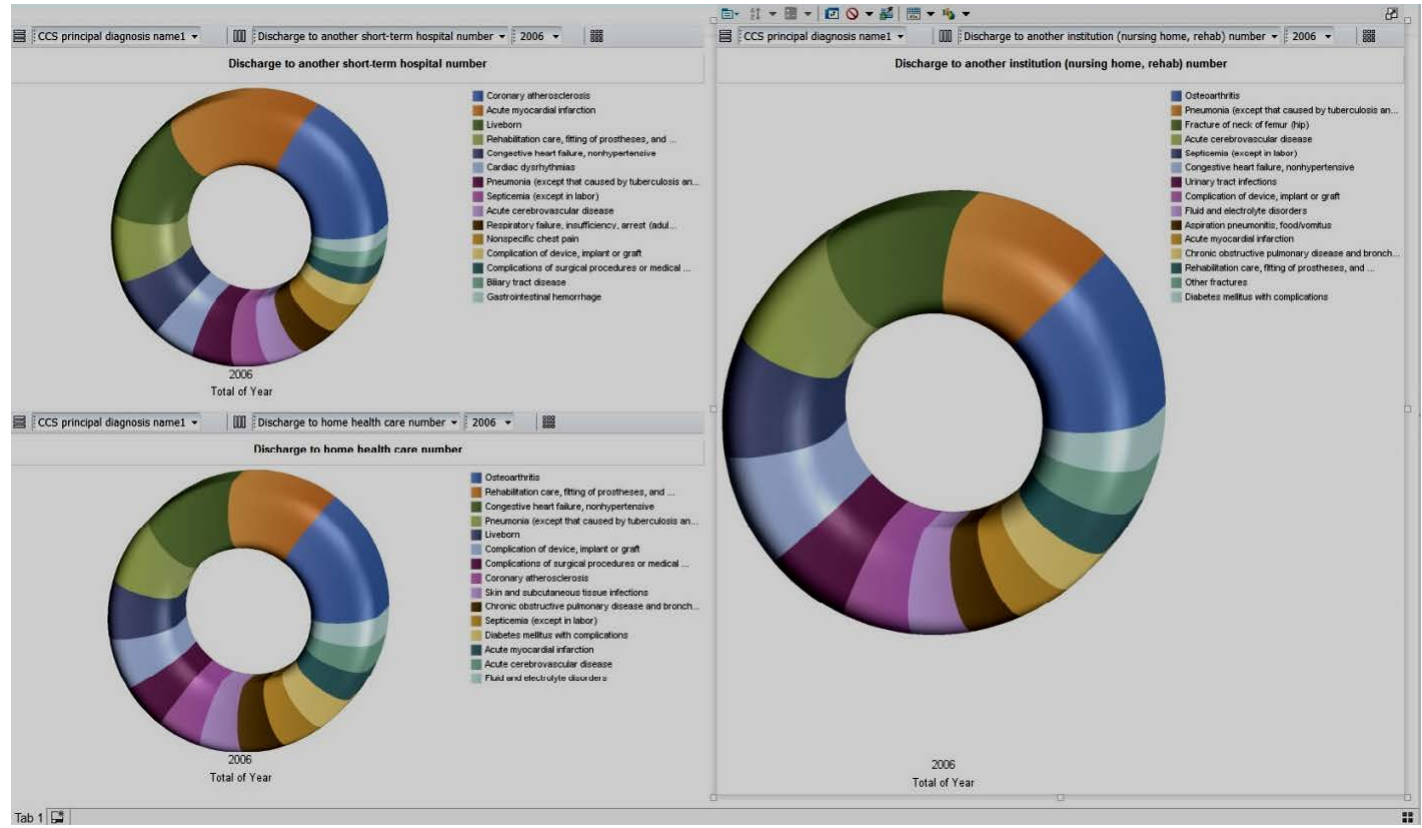

Figure 12: Discharge of patients to other healthcare providers. 
Citation: Raghupathi V, Raghupathi W (2015) Benchmarking Hospital Performance Using Health Analytics. J Health Med Informat 6: 188. doi:10.4172/21577420.1000188

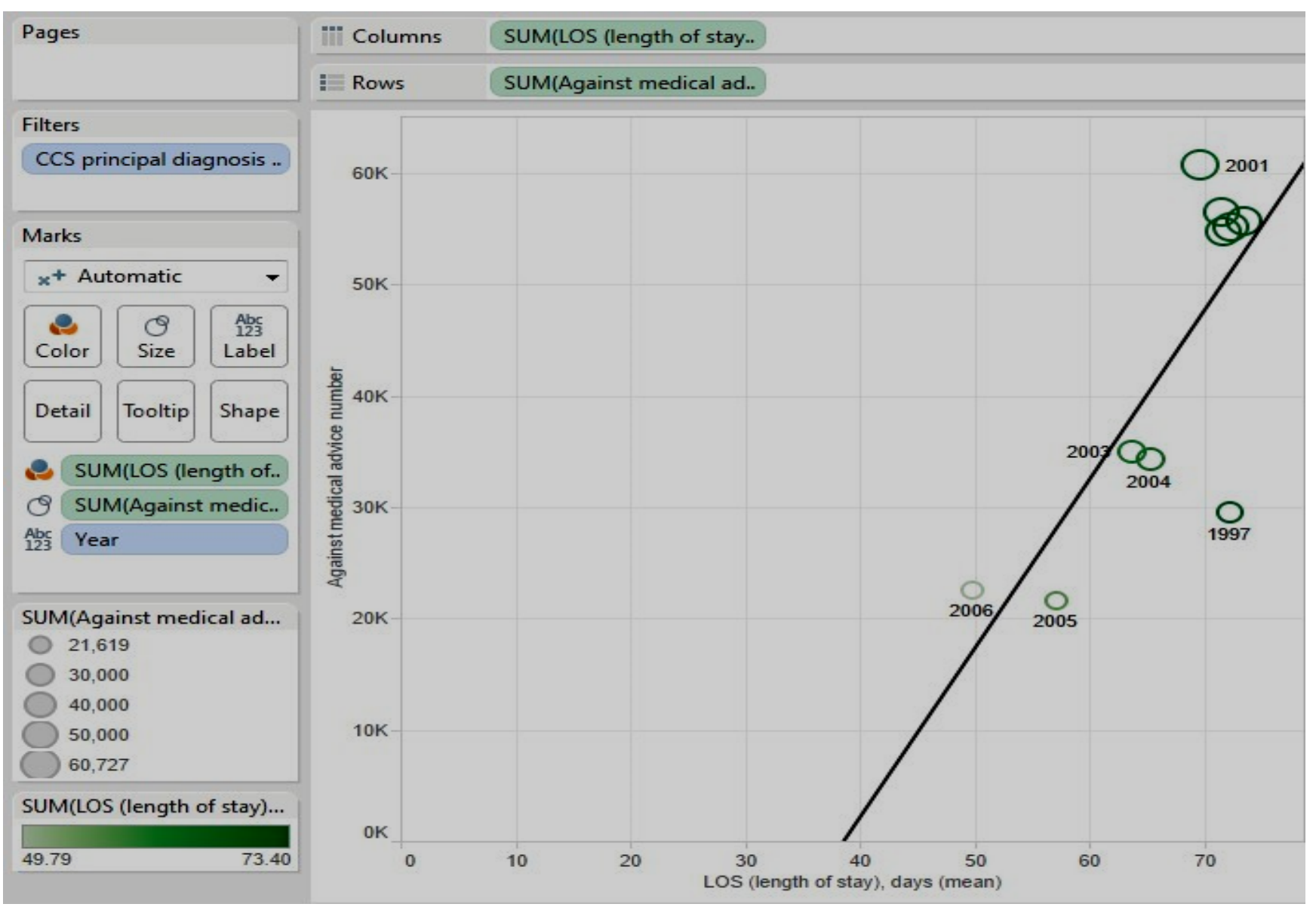

Figure 13: Length of stay and against medical advice.

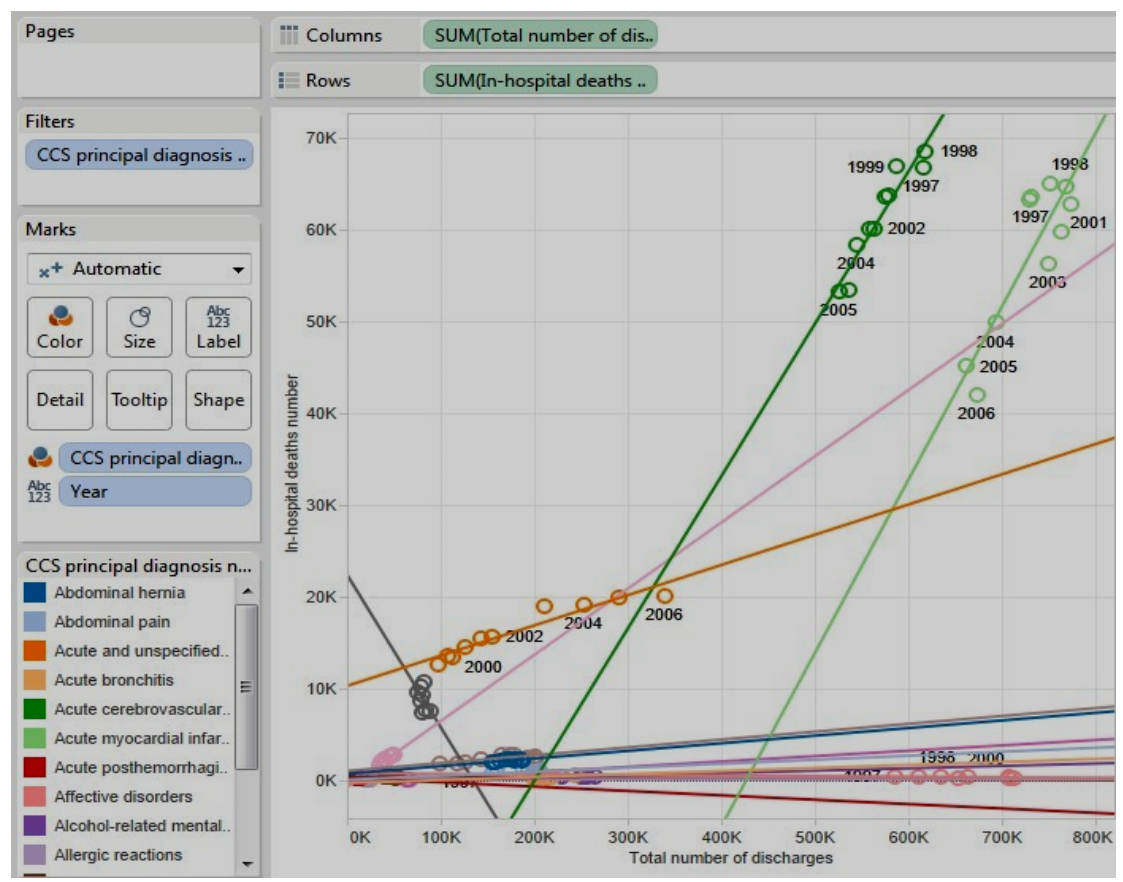

Figure 14: Total number of discharges and number of in-hospital deaths. 
and the relationship between these two numbers, across almost all diseases, is also significant. In the case of acute myocardial infarction, the two indicators showed a decreasing trend over the years. For acute and unspecified renal failure, the two indicators showed an increasing trend. Hospitals should monitor these relationships for various diseases and address how to improve negative trends.

\section{Analysis of hospital charges and national healthcare cost}

We performed a what-if analysis on the national cost given a hypothetical increase in the hospital charges (Figure 15).

Based on historic data, we found that if the total charges for hospitals increased by $10 \%$, the national cost would increase by over $\$ 413$ billion. Analysis like this will help hospitals predict future healthcare costs for various scenarios and plan accordingly. It can also help identify which specific diseases will have the highest impact on overall costs.

From our analyses, hospitals can assess the portfolio of charges for various diseases and make decisions on optimizing overall costs. Our results, which show that during the period of analysis, hospitals have grown more expensive without any incremental discharge benefits to the patients, have major implications for public and national healthcare, and from them, we can propose specific insights into disease management. Hospitals should attempt to reduce the charges (for example, for congestive heart failure) to make treatment more affordable to patients. Hospitals might also consider improving the level of service for diseases that have a history of high death rate (such as liver cancer and septicemea), thereby lowering in-hospital deaths. Hospitals can identify factors that positively impact the discharge rate and also improve the quality of discharge. An ancillary implication is the identification of alternative institutions that patients may be discharged to and the steps required to ensure a smooth and functional transition for each patient in terms of the transfer of medical records and other resources for continuous care. The positive correlation between length of stay and the number of discharges against medical advice indicates that hospitals need to pay attention to determining the length of stay for the portfolio of diseases for which patients are hospitalized. Between 1997 and 2011, the number of discharges against medical advice has increased $41 \%$ in the U.S., and is dominated by 18 44 year olds [5]. This number should be addressed and lowered.

\section{Conclusions}

Hospitals in the U.S. have improved over the years in terms of reducing length of stay, reducing number of in-hospital deaths, and increasing number of discharges from hospitals. However, the cost of healthcare has risen significantly during the same period. Escalating healthcare costs impact the national cost, as we have shown in our analysis.

Meanwhile, the U.S has been rated very low for the quality of healthcare service. Hospitals striving to make themselves marketable to managed care providers and to their patients need to address the negatives, in particular finding ways to improve in the areas of patient care and healthcare delivery. Findings from our study indicate that much is needed to achieve these objectives. Health analytics or clinical analytics will help focus on target areas for improvement and reduce the associated direct cost. We show how patients, healthcare providers and physicians need to be better informed in terms of what's working and what needs improvement.

\section{Scope and limitations}

Limitations to our study include the fact that it covered only a 10 -year period. Future longitudinal studies should cover greater time spans so as to reveal more trends and relationships. Second, while we investigated correlations and trends, we did not include causality across

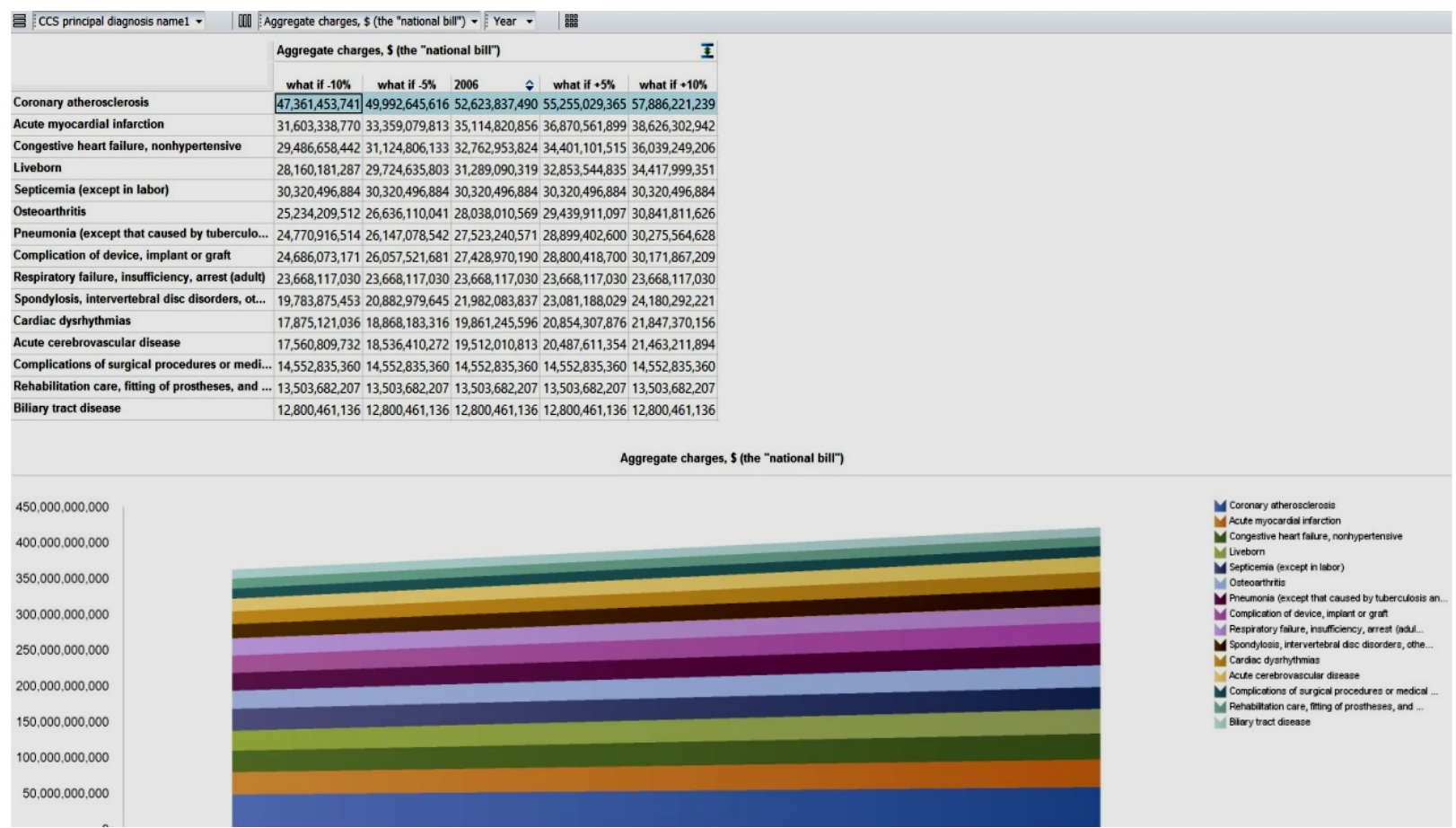

Figure 15: Aggregate charges vs. national healthcare cost. 
the indicators, which future studies can do, thereby helping to identify and target factors that cause increase in healthcare costs and/or decrease in healthcare performance. Third, we utilized a set of indicators that were available in the database of the Agency for Healthcare Research and Quality. There may be other indicators that better explain or offer more valuable insight into the phenomenon of hospital performance. Lastly, we did not account for or remove outliers from our data set, and there were some significant outliers relative to other data. In future studies, the outliers could be removed to understand whether results would differ greatly.

\section{Contributions and policy implications}

Despite limitations, our study contributes to healthcare in several ways. The analysis provides an understanding of how hospitals performed over a recent 10 -year period and whether progress is being made in patient care. Trends over time for key performance indicators - such as total number of discharges, length of stay, dollar hospital charges and in-hospital deaths, - help assess whether progress has been made to improve treatment and/or death rate for certain diseases. Certainly the healthcare system in the U.S. has progressed over the years, but it also has become more expensive. In addition, quality of healthcare requires attention.

Hospital management and health professionals can use this analysis to understand how certain measures have changed in 10 years and focus on improving the weak areas. In addition, the healthcare insurance industry can leverage such analysis for their present and future cost structures. Our results contribute to the arena of healthcare reform, so regulators and government agencies may develop effective policies relevant to hospital management and healthcare delivery.

In terms of future research, there are many possibilities. As stated, future studies can include a more extensive sample, range of indicators, and time span. The indicators from the Agency for Healthcare Research and Quality may be used in conjunction with other healthcare indicators to highlight dimensions that were not captured in this study. In addition, further research can incorporate a global perspective by comparing hospitals in the U.S. to those in other developed countries and discover similarities and differences among the measures. Such a perspective will contribute to reducing global disparities and improving global health.
We also contribute to the methodology of analytics in healthcare. Analytics offers a perfect method for mining and analyzing the immense amount of data available in the healthcare sector. Our study compliments the literature of empirical work that deploys an analytic approach.

Finally, our study helps patients, the most important aspect of the healthcare equation. Patients recognize that hospital performance varies across procedures. They can estimate a specific hospital's performance based on the charges, mortality rates, complications, and other indicators. This is critical since healthcare costs are ultimately passed on to the patients in the form of higher insurance premiums, deductibles, and co-payments. When patients are empowered by information, they can make appropriate healthcare choices as to whether they opt to receive treatment at a particular facility or choose not to avail themselves of any treatment because of the high cost.

\section{References}

1. Hollingsworth $B(2003)$ Non-parametric and parametric applications measuring efficiency in health care. Heathc Manage Sci 6: 203-218.

2. McGlynn EA, Asch SM, Adams J, Keesey J, Hicks J, et al (2003) The quality of health care delivered to adults in the United States. New England J Med 348 2635-2645.

3. Gutierez C, Saloner R, Ranji U (2007) U.S. Healthcare costs: Background Brief. Medicare Patient Management

4. OECD Health Data (2013): How does the United States compare. OECD

5. Pfuntner A, Wier LM, Elixhauser A (Nov 2013) Overview of Hospital Stays in the United States, 2011.

6. World Health Organization (2011): World health statistics 2011. Geneva

7. Schoen C, Osborn R, Squires D, Doty MM (2013) Access, Affordability, and Insurance Complexity Are Often Worse in the United States Compared to 10 Other Countries. 32: 2205-2215.

8. Kearney AT (2013) A healthy dose of data analytics.

9. American Hospital Quality Outcomes (2014): Healthgrades Report to the Nation: Executive Summary.

10. Raghupathi V, Raghupathi W (2013): Exploring the relationship between ICTs and Public Health at a Country level. Int J Healthc Inf Syst Inform 8: 1-22.

11. Raghupathi W, Raghupathi V (2013): An Overview of Health Analytics. J Health Med Informs 4:132.

12. Fleeter TB (2012) When a patient leaves against medical advice. Am Acad Orthop Surg 8. 